\title{
Universidade Federal da Fronteira Sul - Campus Cerro Largo: a percepção da comunidade após cinco anos de sua implantação ${ }^{1}$
}

\author{
Cláudio Machado Maia ${ }^{2}$ \\ Taíz Viviane dos Santos ${ }^{3}$
}

\begin{abstract}
Resumo: Esse estudo apresenta uma percepção da comunidade acadêmica e regional da Universidade Federal da Fronteira Sul (UFFS), Campus Cerro Largo, quanto ao atendimento do campus a missão institucional para a qual foi implantado, em especial a perspectiva de desenvolvimento regional. O objetivo deste estudo é verificar a percepção dos atores sociais, quanto a implantação do campus ao descrever a percepção dos egressos e acadêmicos do campus quanto ao desenvolvimento da região na qual estão inseridos, identificando a aderência do Campus para atender a missão institucional da UFFS. Como estratégia metodológica, optou-se pela abordagem qualitativa, utilizando-se da revisão bibliográfica e documental, e posteriormente realização de perguntas e questionários. Nas considerações finais, pode-se observar que o campus Cerro Largo atende sua missão institucional através do ensino, pesquisa e extensão, assim como atende a perspectiva de sua implantação como estratégia de desenvolvimento regional.
\end{abstract}

Palavras-chave: Desenvolvimento Regional. Educação Superior. Participação Social. Universidade Pública.

Abstract: This study presents a perception of the academic and regional community of the Federal University of the South Frontier (UFFS), Campus Cerro Largo, regarding the campus service the institutional mission for which it was implemented, especially the perspective of regional development. The objective of this study is to verify the perception of the social actors regarding the implementation of the campus by describing the students 'and academicians' perception of the campus regarding the development of the region in which they are inserted, identifying the Campus adherence to attend the institutional mission of UFFS. As a methodological strategy, the qualitative approach was chosen, using a bibliographical and documentary review, and then conducting questions and questionnaires. In the final considerations, it can be observed that the Cerro Largo campus fulfills its institutional mission through teaching, research and extension, as well as the perspective of its implementation as a regional development strategy.

Keywords: Higher education. Public University. Regional development. Social participation.

\section{Introdução}

Em 15 de setembro de 2009, através da Lei n.o 12.029, criou-se a Universidade Federal da Fronteira Sul (UFFS). A lei estabelece que a UFFS tenha por objetivo ministrar ensino superior, desenvolver pesquisa nas diversas áreas do conhecimento e promover a

\footnotetext{
${ }^{1}$ Pesquisa realizada com apoio institucional (bolsa de estudo) da UNOCHAPECÓ.

${ }^{2}$ Doutor em Desenvolvimento Rural. Professor do Programa de Pós-Graduação em Políticas Sociais e Dinâmicas Regionais da UNOCHAPECÓ. claudiomaia.dr@hotmail.com

${ }^{3}$ Mestre em Políticas Sociais e Dinâmicas Regionais. Pesquisadora do Grupo de Pesquisa Desenvolvimento Regional, Política Pública e Governança da UNOCHAPECÓ. taiz29viviane@gmail.com
} 
extensão universitária, caracterizando sua inserção regional mediante atuação multicampi, abrangendo, predominantemente, o norte do Rio Grande do Sul, com campi nos Municípios de Cerro Largo e Erechim, o oeste de Santa Catarina, com campus no Município de Chapecó, e o sudoeste do Paraná e seu entorno, com campi nos Municípios de Laranjeira do Sul e Realeza (BRASIL, 2009).

De acordo com o Plano de Desenvolvimento Institucional (PDI) (UFFS, 2012), a vontade de se ter uma universidade federal na Mesorregião da Fronteira MERCOSUL era antiga e durante anos o assunto foi pauta nos meios de comunicação, nas instituições de ensino e nas mais diversas esferas sociais e políticas. Sendo que, no ano de 2005, entidades, organizações não governamentais (ONGs), lideranças municipais e grupos de municípios, igrejas e movimentos sociais se organizaram em torno da criação do Movimento PróUniversidade Federal, tornando em 2009 o sonho em realidade.

O Movimento Pró-Universidade apostou na construção de uma Universidade Pública e Popular, com a presença das classes populares na universidade e na construção de um projeto de desenvolvimento sustentável e solidário para a região, tendo como eixo estruturador a agricultura familiar e camponesa (UFFS, 2011).

A Universidade Federal da Fronteira Sul, foi criada com a missão de:

\begin{abstract}
assegurar o acesso à Educação Superior como fator decisivo para o desenvolvimento da Mesorregião Grande Fronteira Mercosul, a qualificação profissional e a inclusão social; desenvolver atividades de Ensino, Pesquisa e Extensão buscando a interação e a integração das cidades e estados que compõem a região de inserção da UFFS; e promover o desenvolvimento regional integrado condição essencial para a garantia da permanência dos cidadãos graduados na Mesorregião Grande Fronteira Mercosul e a reversão do processo de litoralização em curso (UFFS, 2015, p.13).
\end{abstract}

O Campus Cerro Largo atende no Rio Grande do Sul as regiões Missões, Celeiro, Noroeste Colonial e Fronteira Noroeste (UFFS, 2011), divisão regional baseada na regionalização realizada no estado do Rio Grande do Sul a partir dos denominados Conselhos Regionais de Desenvolvimento (COREDE). O Campus Cerro Largo, encontra-se implantado no município de Cerro Largo (RS), região das Missões, o qual possui 13.289 habitantes (IBGE, 2010), numa região marcada por grande diversidade étnica e cultural, com cenário econômico e social caracterizado pela baixa renda da população rural, redução de número 
de habitantes do meio rural, e redução da população jovem com acesso ao ensino superior (UFFS, 2011).

Assim, concluída a primeira etapa da implantação do Campus, no período de 2009 a 2015, torna-se importante uma análise da percepção dos atores sociais envolvidos na implantação deste Campus, sobretudo, quanto ao atendimento de sua missão institucional, em especial a perspectiva do desenvolvimento regional, considerando se tratar de um investimento público que envolve grande vulto de recursos.

O Plano Nacional de Educação afirma que nenhum país pode aspirar ao desenvolvido e a independência sem um forte sistema de educação superior com suas funções de ensino, pesquisa e extensão. Ficam as universidades com o desafio da superação das desigualdades sociais e regionais, constituindo-se em instrumento de transmissão de experiência cultural e científica, apropriando-se do saber humano, sendo depositária e criadora do conhecimento (BRASIL, 2001).

Diante deste contexto histórico, este artigo objetiva verificar a percepção de atores sociais (comunidade interna e externa) quanto à implantação da UFFS, Campus Cerro Largo, descrendo a percepção de acadêmicos e de egressos do Campus, em especial quanto aos aspectos de permanência e desenvolvimento da região na qual estão inseridos, identificando a aderência do Campus para atender a missão institucional da UFFS, demonstrando como ocorre o envolvimento dos atores sociais junto à instituição neste campus.

\section{Educação, Região e Desenvolvimento}

A relação entre a educação e o desenvolvimento, bem como a relação entre a educação e a região onde se insere são essenciais, na medida em que é na região que ocorrem as relações humanas e sociais dadas pela história e pela geografia e que se reproduzem ao longo dos anos.

A noção de região e de desenvolvimento, adotada nesse estudo, é desenvolvida por Paiva (2005), onde se destaca que "região" não é apenas uma entidade física e sim uma construção social onde o desenvolvimento endógeno é um processo de ampliação do bem estar da população. "Entendemos por "desenvolvimento" a ampliação sustentável (nos 
planos econômico, social e ambiental) da oferta e da apropriação de bens materiais e culturais por parte de uma determinada comunidade" (PAIVA, 2005, p.2).

Assim, entre os recursos existentes em uma determinada região, encontra-se o chamado capital social, os traços culturais característicos de uma comunidade e que, conforme Bandeira (1999, p. 20) "contribuem para fazer que seus membros se tornem propensos a colaborar na solução de problemas de interesse social". Ainda, de acordo com o autor, embora tenha se dado maior atenção ao capital social, seu reconhecimento ainda é incipiente no campo das políticas públicas (BANDEIRA, 1999). Qualquer região que almejar o desenvolvimento precisa de políticas voltadas para uma educação de qualidade, fator fundamental para apropriação de conhecimento e fortalecimento do capital social de uma região.

De acordo como o Plano de Desenvolvimento da Educação (BRASIL, 2007), o enlace entre a educação e o desenvolvimento é essencial na medida em que é por meio dele que se visualizam e se constituem as interfaces entre a educação como um todo e as outras áreas de atuação do Estado.

Não importa a abrangência do território considerado, o bairro ou o país. A relação recíproca entre educação e desenvolvimento só se fixa quando as ações do Estado são alinhadas e os nexos entre elas são fortalecidos, potencializando seus efeitos mútuos. Desse movimento de busca de sintonia das políticas públicas entre si depende a potencialidade dos planos setoriais, inclusive o educacional, que passam, nesses termos, à condição de exigência do desenvolvimento econômico e social, garantindo-se que o todo seja maior que a soma das partes (BRASIL, 2007, p. 5-6).

Assim, é importante a observação de que o processo de desenvolvimento vai muito além de aspectos puramente econômicos. Portanto, deve-se considerar para esse trabalho o tema "desenvolvimento" em seu processo amplo, englobando a economia, mas também a sustentabilidade, a qualidade de vida, os aspectos sociais, humanos e educacionais.

\section{Abordagem teórica sobre desenvolvimento regional}

Verifica-se na literatura sobre desenvolvimento regional que vários fatores devem ser considerados para o desenvolvimento de uma determinada região, debtre os quais, citase o mercado, a economia, a sociedade civil, a sustentabilidade humana e social e a própria 
globalização. Ribeiro (2008) ensina que o campo de desenvolvimento é constituído por atores sociais que representam vários segmentos da população, ou seja, elites locais e líderes de movimentos sociais, empresários privados, funcionários e políticos em todos os níveis de governo, pessoal de corporações nacionais, internacionais, transnacionais, e pessoal de organizações internacionais de desenvolvimento.

Para o processo de desenvolvimento atual, têm-se duas ordens de determinação. Uma definida pelo primado econômico, devastando nações e regiões e outra perseguida pelas sociedades regionais e nacionais, reagindo a esta devastação. Dessa contradição surge o movimento através da esfera econômica - mercado auto-regulável/globalização e o contra movimento da esfera social - a auto-proteção da sociedade organizada. Nesse contexto, ensina Gramsci (1975), a esfera política entra como espaço de mediação entre a esfera econômica e a esfera social, assim engloba-se num único contexto, as esferas do desenvolvimento contemporâneo: a economia, o social e a política (BECKER, 2001). Portanto, um dos desafios do desenvolvimento está na apropriação dos projetos pela sociedade e instituições locais. Para Ribeiro (2008), é preciso que as populações e instituições locais se percebam como sujeitos ativos do processo de desenvolvimento, senão a apropriação dos projetos locais continuará sendo um problema, reforçando as desigualdades.

De acordo com Bandeira (1999) e Maia e Santin (2015), a ideia de que se faz necessário a criação de mecanismos que possibilitem a participação social, no detalhamento e na implantação de políticas públicas vem crescendo no Brasil. E isso pode ser atribuído, por um lado, ao avanço democrático do País, e por outro, à abordagem no contexto internacional da importância da participação social e da articulação dos atores sociais para ações relacionadas ao desenvolvimento.

Entende-se que para operacionalizar um processo de desenvolvimento regional "de baixo para cima" é necessária a mobilização endógena e por sua vez mobilização dos recursos locais, entre eles os recursos humanos (HADDAD, 1993). Nesse sentido, Paiva (2005, p.3) afirma que "se os recursos mobilizados são propriedade de habitantes da região ou são de propriedade coletiva da comunidade regional, então o desenvolvimento é endógeno". Para Bandeira (1999), as bases competitivas de uma região são reforçadas a 
partir da participação e da articulação dos atores sociais regionais a partir da contribuição para acumulação de capital social e de consensos básicos relevantes para o desenvolvimento.

Quanto à relação global/local, Becker (2001, p.31) entende que "a criação de um espaço global, abstrato e homogêneo, gera um espaço local, concreto e heterogêneo, de desenvolvimento". Com a melhoria da comunicação e o acesso imediato à informação, torna-se possível a articulação do local ao global, assim Diniz $(2000$, p. 7) afirma que a globalização deve ser vista como um processo contraditório e não como um fim em si mesmo, e que o sucesso econômico de cada região depende "da capacidade de se especializar naquilo que consiga estabelecer vantagens comparativas efetivas e dinâmicas, decorrentes de seu estoque de atributos e da capacidade local de promoção continuada de sua inovação".

Observa-se que o desenvolvimento, alicerçado apenas pelo primado econômico, migra para o desenvolvimento primado no conhecimento, que mobiliza a sociedade regional em um contra movimento do mercado auto-regulável e se beneficia da chamada globalização. Desta forma, o capital social constitui um dos principais ativos do desenvolvimento regional.

Assim, para o desenvolvimento primado no conhecimento, torna-se importante a formação acadêmica da sociedade regional, através de uma instituição de ensino superior que possa fortalecer o capital social da região através do ensino, pesquisa e extensão, pois na era do conhecimento, educação deve ser vista como base estrutural que assegura o exercício da cidadania.

\section{0 papel das universidades no desenvolvimento regional}

A capacidade de uma nação de gerar conhecimento e reverter conhecimento em riqueza e desenvolvimento social depende da ação de alguns agentes institucionais. Entre estes, a universidade e o governo estão entre os principais agentes institucionais geradores de conhecimento (CRUZ, 2000). 
Para Borges (2010), a educação é um processo social, elemento de um conjunto cultural sistematizado para servir aos interesses da sociedade, da economia e da política em nosso país, e não apenas um fato isolado. A educação superior através das universidades vem contribuindo significativamente para transformação da sociedade, formando massa crítica e pessoas qualificadas, que estão sendo chamadas a desenvolver um papel fundamental para o desenvolvimento regional.

Em uma mudança da universidade pública pela perspectiva de formação e da democratização é preciso se colocar claramente contra a exclusão, tomar a educação superior como direito do cidadão, assegurar simultaneamente a universalidade dos conhecimentos e a especificação regional. E, ainda, revalorizar a pesquisa, onde a avaliação dos pesquisadores não sejam regidos pelas noções de produtividade e de eficácia e sim pelas de qualidade e de relevância social e cultural, cabendo a universidade e ao Estado levantar as necessidades. Assegurando, assim, que haja diversificação dos campos de pesquisa segundo as capacidades e necessidades regionais (CHAUI, 2003).

Tendo como base, o Plano de Desenvolvimento da Educação (2007), o mesmo está sustentado em seis pilares. Estes são a visão sistêmica da educação, territorialidade, desenvolvimento, regime de colaboração, responsabilização e mobilização social. Estes "são desdobramentos conseqüentes de princípios e objetivos constitucionais com a finalidade de expressar o enlace necessário entre educação, território e desenvolvimento" (BRASIL, 2007, p. 10).

Não se pode negar que há uma estreita ligação entre educação e desenvolvimento. A educação é um fator de extrema relevância para se alavancar o desenvolvimento de um país, onde a contribuição das universidades para o desenvolvimento é inquestionável. No entanto, ressalta-se que a literatura a cerca da contribuição das mesmas para o desenvolvimento em suas regiões é incipiente (SERRA; ROLIM, 2013).

A preocupação da contribuição das universidades para o desenvolvimento regional é recente e deriva de alguns fatores, tais como, o intenso processo de globalização, um novo olhar sobre a competitividade das regiões e uma nova interpretação acerca dos sistemas regionais de inovação. Assim, o engajamento das universidades com outros atores sociais é fundamental para responder as necessidades da região (ROLIM; SERRA, 2009). "O 
engajamento das instituições de ensino superior significa, em última instância, o compromisso efetivo destas com o desenvolvimento econômico, social e cultural de suas próprias regiões" (SERRA; ROLIM, 2013, p.84).

A participação das universidades para o processo de desenvolvimento regional, também foi lembrada no documento de referência da I Conferência Nacional de Desenvolvimento Regional (2012). Entre os princípios balizadores da Política Nacional de Desenvolvimento Regional (PNDR), está a participação da sociedade civil, onde além dos entes federados e dos órgãos governamentais, a PNDR supõe a participação dos segmentos sociais organizados, entre eles as universidades, para que apresentem, através de fóruns ou canais apropriados, diversidades e potencialidades territoriais e regionais (CNDR, 2012).

O documento ainda apresenta como um dos eixos temáticos e diretrizes específicas sugeridas para a PNDR, o Desenvolvimento Produtivo Sustentável, que por sua vez, possui entre suas vertentes a educação e a ciência, tecnologia e inovação. Tais vertentes trazem como diretrizes sugeridas, orientando a rede pública de ensino médio, profissionalizante e universitário a priorizar os interesse e necessidades das populações do campo, indígenas, quilombolas, afro descendentes, mulheres de baixa renda e das pessoas com deficiência e fomentar o desenvolvimento e a difusão de tecnologias de produção e gestão com foco na Agricultura Familiar (CNDR, 2012).

Tudo isso se encontra em consonância com o que estabelece o próprio Plano Nacional de Educação, o qual afirma que nenhum país pode aspirar a ser desenvolvido e independente sem um forte sistema de educação superior.

\footnotetext{
Num mundo em que o conhecimento sobrepuja os recursos materiais como fator de desenvolvimento humano, a importância da educação superior e de suas instituições é cada vez maior. Para que estas possam desempenhar sua missão educacional, institucional e social, o apoio público é decisivo (BRASIL, 2001, p. 27).
}

Portanto, a disponibilidade regional de conhecimentos e capacidades pode fazer das universidades, regionalmente engajadas, um elemento-chave no processo de desenvolvimento socioeconômico regional (SERRA; ROLIM, 2013). Por outro lado, para Benincá (2011), vigoram diferentes visões acerca da importância, da orientação e da finalidade da universidade, onde algumas se alinham na defesa da educação como meio 
essencial para a formação de cidadãos aptos a promover o desenvolvimento social, justo e equitativo.

Para Kraemer (2006), a universidade é, dentre várias instituições de ensino formal, aquela que compete,

Ministrar o mais elevado grau de ensino, o superior, ou seja, o da educação para máxima capacidade e qualificação dos seus cidadãos na resolução e antecipação dos problemas que mais os afetam. E para cumprir esta missão, a universidade busca incessantemente as raízes e soluções desses problemas, por meio da investigação e do desenvolvimento de metodologias e ferramentas novas (KRAEMER, 2006, p.23).

Citando Kornhauser (2001), Kraemer (2006), dispõe que:

A educação é o cimento da construção do desenvolvimento sustentável. É preciso elaborar estratégias e programas relacionados com o ambiente, que abranjam tanto o ensino escolar como a educação informal, que adotem a perspectiva da educação permanente a ser desenvolvida pelos poderes públicos, o setor produtivo, o comércio e as comunidades locais (KORNHAUSER, 2001, p.236 apud KRAEMER, 2006, p.9).

Para cumprir sua finalidade, as universidades necessitam dar um retorno concreto à sociedade, em especial na região em que está inserida, onde através do tripé ensino, pesquisa e extensão possa melhorar a qualidade de vida da sociedade e proporcionar o desenvolvimento regional sustentável. Nesse contexto de enlace entre educação, desenvolvimento, região, formação de capital social e participação social, encontram-se a Universidade Federal da Fronteira Sul (UFFS), que além do papel primordial de ensino, pesquisa e extensão, busca a redução das desigualdades, a inclusão social e o fortalecimento dos indivíduos para o exercício da cidadania.

\section{UFFS - Campus Cerro Largo}

Na cidade de Cerro Largo, no antigo Seminário São José, localiza-se o Campus provisório da UFFS (Unidade Seminário). A edificação é patrimônio da UFFS desde 2010 e conforme indica o PDI (2012) posteriormente será reformado para contemplar a demanda por moradia estudantil. 
Os dois terrenos do campus de Cerro Largo, onde se encontram as novas instalações (sede definitiva), localizam-se próximos ao centro comercial da cidade. Com quase 655.000 $\mathrm{m}^{2}$, essas instalações estão localizados sobre a Avenida Jacob Reinaldo Haupenthal, próximos ao Parque Municipal de Exposições, a uma distância de $2 \mathrm{~km}$ da praça central onde se desenrola o núcleo urbano. Nesses terrenos já foram construídos o Bloco $A$, três Blocos de Laboratório, o Restaurante Universitário e encontra-se em construção o Bloco de Salas dos Professores (UFFS, 2015).

A história do Campus Cerro Largo reflete a história da Universidade Federal da Fronteira Sul (UFFS), em especial no aspecto da participação social para sua conquista. Treib e Rotta (2012) afirmam que a criação da UFFS é resultado de uma intensa mobilização da sociedade civil organizada das regiões Norte e Noroeste do estado do Rio Grande do Sul, Oeste de Santa Catarina e Sudoeste do Paraná. "Na região Noroeste do Rio Grande do Sul (RS), o movimento envolveu parcelas significativas da população e deixou marcas que servem de referência para os primeiros passos da constituição do Campus Cerro Largo da UFFS" (TREIB; ROTTA, 2012, p. 3).

A participação social está na origem da criação da UFFS e do próprio Campus Cerro Largo. A escolha do município de Cerro Largo para sediar o Campus na região Noroeste do Rio Grande do Sul, se deu no dia 10 de dezembro de 2007, no município de São Luiz Gonzaga, em reunião convocada pelo comitê executivo pró-universidade pública federal da região missões (MOVIMENTO PRÓ-UNIVESIDADE, 2007).

No decorrer da história da UFFS - Campus Cerro Largo, a participação social e a interação com a comunidade regional, movimentos sociais e entidades da região, demonstram-se expressivas e são percebidas. Entre outras, percebe-se na participação social junto ao conselho comunitário e ao Conselho Estratégico Social.

\section{Procedimento Metodológico}

Como metodologia de pesquisa, optou-se pela abordagem qualitativa, uma vez que esta é um meio para explorar e entender a relação dinâmica entre a universidade e o desenvolvimento regional, bem como as perspectivas em torno deste contexto. 
Após a análise bibliográfica e documental, passou-se a pesquisa in loco se utilizando da técnica de entrevistas individuais, de forma semi-estruturada junto aos servidores técnicos administrativos, docentes e gestores do Campus Cerro Largo, comunidade regional e gestores da Reitoria. Já os questionários foram aplicados presencialmente com os discentes do campus e na forma eletrônica com os primeiros egressos do campus.

A partir disso, apresenta-se a percepção da gestão, docentes, técnicos, discentes e atores sociais envolvidos nas atividades cotidianas do Campus Cerro Largo, quanto a missão institucional da UFFS em especial no que tange a promoção do desenvolvimento regional, a permanência do jovem da região e a participação social.

\section{Resultados e discussões}

Observada a primeira fase de implantação do Campus Cerro Largo, constata-se que o campus possui forte aderência a missão institucional da UFFS, proporcionando fortemente a participação social, assegurando e proporcionando, através de suas atividades de ensino, pesquisa e extensão, a qualificação profissional, a inclusão social e a interação com a comunidade regional. Ressalta-se, não ser possível mensurar em números ou cifras, o investimento em capital humano, social e cultural que isso representa.

Sinaliza-se através da pesquisa realizada com os primeiros egressos e com os atuais acadêmicos, o desejo da maioria em permanecer na região e assim contribuir para o desenvolvimento regional integrado e sustentável. Também, manifesta-se a importância do Campus Cerro Largo em suas vidas e a contribuição deste para sua formação profissional, social e humana.

Os egressos e acadêmicos pesquisados acreditam que a UFFS - Campus Cerro Largo pode contribuir para o desenvolvimento regional, sendo que para muitos isso se dará à longo prazo. Indagados sobre qual aspecto o campus contribui para o desenvolvimento regional foram citados os aspectos social, cultural, humano, econômico, de bem estar e qualidade de vida.

A definição de região e de desenvolvimento, aplicada nesse estudo, a região não é apenas uma entidade física e sim uma construção social e se entende por desenvolvimento 
“a ampliação sustentável (nos planos econômico, social e ambiental) da oferta e da apropriação de bens materiais e culturais por parte de uma determinada comunidade" (PAIVA, 2005, p. 2). Com isso, então, percebe-se que a implantação da UFFS - Campus Cerro Largo foi uma estratégia de desenvolvimento regional válida, em especial pela sua forma de implantação "de baixo para cima" protagonizada pela sociedade civil organizada, através de seus movimentos sociais, que se constituíram em um movimento unificado denominado como pró-universidade.

A comunidade acadêmica e regional sinaliza o reconhecimento do Campus Cerro Largo como estratégia de desenvolvimento regional pelo seu ensino público, gratuito e de qualidade, bem como pelo seu caráter popular. O campus vem proporcionando o acesso aos menos favorecidos, o desenvolvimento humano e social dessa classe, mantendo seu compromisso com a escola pública e primando pela educação pública de qualidade, destacando-se o programa de formação de professores envolvendo diversas instituições de ensino da região missioneira.

Também, destaca-se pela comunidade acadêmica e externa que nesse primeiro momento, considerado o cenário atual (2015) e o leque de cursos ofertados pelo Campus, a universidade consegue desenvolver na região um papel muito relevante no ensino. Observase a grande perspectiva, em especial pela comunidade externa, pela implantação de novos cursos de graduação, especializações, mestrados e doutorados, bem como de novos campi e/ou expansão de cursos de graduação do Campus Cerro Largo em outros municípios na região.

Na extensão, destacaram-se as áreas de licenciatura, em especial pelo programa de formação de professores e os estágios de acadêmicos junto às escolas da região. Por outro lado, para extensão, nas áreas que envolvem os cursos de bacharelado, em especial os cursos de agronomia e engenharia ambiental, sinaliza-se uma grande perspectiva. Em médio prazo, por meio de um número maior de projetos envolvendo a agricultura familiar e camponesa, observando-se que há o entendimento de que atualmente, considerado o curto período de implantação da UFFS, o restrito número de servidores, muitas vezes, impossibilita o quantitativo de projetos de extensão desejados pela comunidade regional. 
Naturalmente, a comunidade acadêmica e principalmente a comunidade externa possuem grande perspectiva, em um médio e longo prazo, quanto às possibilidades de pesquisas tanto nas áreas que envolvem os cursos de licenciaturas quanto nas áreas que envolvem os cursos de bacharelados. Tal perspectiva se reforçou com a criação do primeiro programa de mestrado do Campus, iniciado em 2015, voltado para o desenvolvimento e para as políticas públicas.

Cabe observar que é clara a visão da comunidade acadêmica e parte da comunidade externa, que ao se tratar da implantação de uma universidade como estratégia de desenvolvimento regional. Esse fator ocorre principalmente em função das atividades de ensino, pesquisa e extensão, proporcionados pelo mundo acadêmico em interação com a comunidade regional.

Manifesta-se que respeitado o tempo necessário para implantação e consolidação da instituição, grande parte dos anseios da sociedade são possíveis de serem atendidos. Entre os anseios da sociedade que não são possíveis atender, estão os aspectos mais delicados, que fogem do limite de autonomia da universidade (intervenções diretas/prestação de serviço que não são atribuições diretas do ensino, pesquisa e extensão).

No entanto, as opiniões dos segmentos da comunidade acadêmica se dividem quando se trata do anseio da comunidade regional de criação de novos campi na atual região de abrangência do Campus Cerro Largo ou na oferta de turmas de cursos de graduação nos municípios da região (uma espécie de expansão da UFFS - Campus Cerro Largo).

A aposta do movimento pró-universidade, na construção de uma universidade pública e popular, até o momento, demonstra-se garantida pelo Campus Cerro Largo, pois é possível observar a forte presença das classes populares na universidade, sendo que dos 274 acadêmicos pesquisados. Quase a totalidade destes são originários da região de abrangência do campus Cerro Largo, sendo 181 discentes de origem rural (66\%) e 255 discentes oriundos de escola pública (93\%). A forte dinâmica de participação social e a dinâmica administrativa e acadêmica do campus Cerro Largo, em especial em proporcionar e respeitar essa participação social, até então, também sinalizam para manutenção desse projeto de 
desenvolvimento sustentável e solidário, tendo como eixo a agricultura familiar e camponesa.

No entanto, reconhece-se que são muitos os desafios para manutenção desse projeto diferenciado de universidade, uma vez que a missão institucional da UFFS é ampla e complexa. Assim, para ser atendida em sua plenitude, além da vontade da comunidade acadêmica, da comunidade regional e da gestão da instituição, depende de fatores externos, citando-se como exemplo, a vontade de parceria de outras instituições e da mobilização regional para absorção dos profissionais egressos do Campus.

Também, reconhece-se que por diversos fatores condicionantes não será possível, manter a demanda total de egressos na região, o que já ocorre naturalmente em outras universidades. Muitos de seus egressos migram para outras regiões em busca de oportunidade, da mesma forma que jovens de outras regiões migram para região do campus a fim de realizar sua graduação e após sua conclusão permanecem na região.

As etapas de criação e implantação da UFFS - Campus Cerro Largo estão sendo cumpridas, o que se espera é uma universidade com excelência acadêmica, consolidada, com programas de ensino, pesquisa e extensão robustos e bem constituídos. Uma universidade, que aprenda a lidar com as diferenças e divergências, pois as divergências ajudam a construir a universidade. As expectativas é de que a UFFS se transforme em um polo reconhecido de geração de conhecimento e tecnologias, formando profissionais cientes de suas responsabilidades sociais de inclusão; uma universidade que se integre cada vez mais com estados, cidades, países, universidades, com eventos e fóruns de participação. Uma universidade formada de indivíduos críticos de suas atitudes, politizados e cientes de suas responsabilidades individuais e perante a sociedade.

\section{Considerações finais}

Esse estudo destaca a importância do ensino superior gratuito, público e popular ofertado por uma instituição de ensino superior em uma região de fronteira marcada por grande diversidade étnica e cultural e com um cenário econômico e social caracterizado pela 
baixa renda, em especial da população rural, e até então desprovida de universidades públicas federais.

O Campus Cerro Largo, demonstra desde sua essência a importância da participação social, em especial através de movimentos sociais, da sociedade civil organizada. Em consonância a isso é importante observar que o campus está implantado na chamada região missioneira a qual tem em sua origem e essência o sistema de cooperativismo, ou seja, a associação de pessoas ou grupos com os mesmos interesses, a soma de esforços, o auxílio mútuo.

Verificou-se a comunidade externa, a percepção dos acadêmicos e egressos, a percepção dos servidores e gestores, bem como a aderência do campus para atender a missão institucional da UFFS e promover a participação social junto à instituição, na perspectiva de compreensão de uma estratégia de desenvolvimento regional.

Assim, considerando que a UFFS foi criada em 2009, sendo que as atividades acadêmicas do Campus Cerro Largo iniciaram em 2010, sugere-se que estudos futuros possam aprofundar a temática em torno das conseqüências e impactos de desenvolvimento regional, causados em função da implantação da UFFS na região macro missioneira.

Este estudo contribui para o estudo da contribuição da educação para o desenvolvimento regional, em especial o papel das universidades nesse processo. Da mesma forma, reflete sobre a importância da participação social e sua força através da sociedade civil organizada, força esta que se tornou determinante para implantação da Universidade Federal da Fronteira Sul.

\section{Referências}

BANDEIRA, Pedro. S. Participação, Articulação de Atores Sociais e Desenvolvimento Regional. IPEA. Textos para discussão, n.630. Brasília: fev.1999.

BECKER, Dizimar. F. A economia política da regionalização do desenvolvimento contemporâneo. In: A economia política do desenvolvimento regional. Redes. v.6, n.3, set/dez.2001.

BENINCÁ, Dirceu. Universidade e suas fronteiras. São Paulo: Outras expressões, 2011. 
BORGES, Marcos A. M. Movimentos Sociais e Educação. Políticas Públicas em Educação. Brasília: CETEB, 2010.

BRASIL. Lei $n^{\circ}$ 10.172, de 09 de janeiro de 2001. Aprova o Plano Nacional de Educação e dá providências. Brasília: Diário Oficial da União, 2001.

Ministério da Educação. Plano de Desenvolvimento da Educação: razões, princípios e programas. Brasília: 2007.

Lei $\mathrm{n}^{\circ}$ 12.029, de 15 de setembro de 2009. Institui a Universidade Federal da Fronteira Sul - UFFS. Brasília: Diário Oficial da União, 2009.

CHAUI, Marilena. A universidade pública sob nova perspectiva. Revista Brasileira de Educação, n. 24, p. 5, São Paulo: 2003.

Conferência Nacional de Desenvolvimento Regional, I, 2012, Brasília: Secretaria de Desenvolvimento Regional, 2012. Disponível em:

http://www.integracao.gov.br/c/document_library/get_file?uuid=54bce099-503a-40768613-d90dd6107c79\&groupld=10157. Acesso em: 24 mai.2018.

CRUZ, Carlos H. B. Universidade, a Empresa e a Pesquisa que o país precisa. Brasília, 2000. Parceiras estratégicas. n.1, p.5. Brasília: MCTE, 2000.

DINIZ, Clelio C. Global-Local: Interdependências e Desigualdade ou Notas para uma Política Tecnológica e Industrial Regionalizada no Brasil. Rio de Janeiro: IE/UFRJ, julho.2000.

GRAMSCl, Antonio. Quaderni del cárcere. Torino: Enaudi, 1975

HADDAD, Paulo R. Regiões, regionalismo e desequilíbrios regionais: algumas reflexões. Porto Alegre: FEE/Revista Eletrônica, 1993.

IBGE. Instituto Brasileiro de Geografia e Estatística. Censo 2010. Disponível em:<https://censo2010.ibge.gov.br/ $\geq$. Acesso em: 24 mai 2018.

KRAEMER, Maria E. P. O ensino universitário e o desenvolvimento sustentável. Curitiba: UFPR, 2006.

MAIA, Claudio Machado; SANTIN, Myriam Aldana Vargas. A participação social nos processos de decisão na construção regional. Relato de Experiência PROESDE/2014 - Unochapecó.

Revista Extensão em Foco, Caçador/SC, v.3, n.1. p.199-207, 2015.

MOVIMENTO PRÓ-UNIVERSIDADE. Comissão De Implantação - Campus Missões, São Luiz Gonzaga. Ata da reunião realizada no dia 10 de dezembro de 2007.

PAIVA, Carlos A. N. Regionalização com vistas ao planejamento do desenvolvimento endógeno sustentável. In: Anais nas Primeiras Jornadas de Economia Regional Comparada. Porto Alegre: FEE/PUCRS, 2005. 
RIBEIRO, Gustavo L. Poder, redes e ideologia no campo do desenvolvimento. São Paulo: Cebrap, n. 80, mar.2008. Disponível em: http://www.scielo.br/pdf/nec/n80/a08n80.pdf. Acesso em: 24 mai. 2018.

ROLIM, Cássio F. C.; SERRA, Maurício A. Universidade e Desenvolvimento Regional: O apoio das instituições de ensino superior ao desenvolvimento regional. 1ạ Ed. Curitiba: Juruá, 2009.

SERRA, Maurício A.; ROLIM, Cássio F. C. Desenvolvimento e engajamento regional: o papel das universidades. In: SILVEIRA, Rogério L.L. (Org.) Observando o Desenvolvimento Regional Brasileiro: Processos, Políticas e Planejamento. Santa Cruz do Sul: EDUNISC, 2013.

TREIB, Rafael Rodrigo Wolfart; ROTTA, Edemar. Projeto de iniciação científica: O processo sócio-histórico de implantação da Universidade Federal da Fronteira Sul, Campus Cerro Largo. Cerro Largo: UFFS, 2012.

Relatório de Gestão Pró-Tempore 2009-2015. Chapecó: UFFS, 2015.

Projeto Pedagógico do Curso de Graduação em Administração do Campus Cerro Largo. Cerro Largo: UFFS: 2011. Disponível em: https://www.uffs.edu.br/atosnormativos/ppc/ccadmcl/2015-0001. Acesso em: 24 mai.2018.

Plano de Desenvolvimento Institucional. Chapecó: UFFS: 2012. Disponível em: https://www.uffs.edu.br/institucional/a_uffs/a_instituicao/plano_de_desenvolvimento_insti tucional $\geq$. Acesso em: 24 mai. 2018. 